\title{
A Fast and Facile Synthesis of Geometric Isomers of 4-Cinnamylidene-2-Phenyl-2- Oxazolin-5-One and their Stereospecific Solvolysis Products
}

\author{
Priyanka Borah ${ }^{1}$, Bornana Saikia ${ }^{2}$ and Pradeep K. Tripathy ${ }^{3 *}$ \\ Department of Chemistry, North Eastern Regional Institute of Science \& Technology, \\ Nirjuli-791109, Itanagar, Arunachal Pradesh, India ${ }^{1,2,3}$
}

\begin{abstract}
The classical Erlenmeyer Azlactone Synthesis is one of the most common reactions to produce Azlactones or 5(4H)-Oxazolones. The process consists of cyclodehydration- condensation of different arylaldehydes with hippuric acid in acetic anhydride in the presence of anhydrous sodium acetate as a homogeneous base catalyst. The procedure generally produces a mixture of geometrical isomers of $E$ and $Z$. In the present investigation, a disciplined route for the synthesis of either $E$ or $Z$-isomer is developed. The conversion of $\alpha$-N-Benzoyl glycine i.e. Hippuric acid (1) to unstable 2-phenyl-2-oxazolin-5-one (2) was carried out in dry benzene using either ethyl chloroformate or benzene sulphonyl chloride or $p$-toluene sulphonyl chloride as cyclizing agent in the presence of triethylamine base at room temperature. Then the condensation of cinnamaldehyde with $\mathbf{2}$ is carried out by refluxing the content for 10 minutes. The solvent was removed under reduced pressure. The unsaturated azlactone obtained, $(E)$-4-cinnamylidene-2-phenyl2-oxazolin-5-one (3) can be isolated by triturating it with ethanol or may be subjected to solvolysis directly. Hydrolysis, alcoholysis and aminolysis of (E)-4-cinnamylidene-2-phenyl-2-oxazolin-5-one (3) leads to the formation of corresponding dehydroamino acid (4), esters of dehydroamino acid (5) and alkenamide (6) respectively by the cleavage of 1,5- bond of the azlactone (3) with $(E)$-configuration maintaining the steric integrity at 4-position of $(E)$-azlactone. $(E)$-azlactone (3) can be converted to (Z)-azlactone (7) by boiling it in dry pyridine for 15 minutes. Similar way, the solvolysis of 1, 5-bond of (Z)-isomer of 4-cinnamylidene-2-phenyl-2-oxazolin-5-one (7) affords the solvolysis products with $(Z)$-configuration. For each of the product formation, all the required steps are carried out in the same flask.
\end{abstract}

Keywords: Geometric isomers, 4-Cinnamylidene-2-phenyl-2-oxazolin-5-one, Stereospecific, Solvolysis, Disciplined route.

\section{INTRODUCTION}

2-Oxazolin-5-ones, also called 5-(4H)-Oxazolones, continue to attract attention of chemists because of their usefulness as synthons and their diverse biopotentiality. The subject has been reviewed ${ }^{1-8}$ from time to time. 2-Oxazolin-5-ones (III) are usually synthesized by the cyclization of $\alpha$-N-acylamino acids (I) with the help of different cyclizing agents followed by the condensation with carbonyl compounds. 2-Substituted 4-arylmethylene-2oxazolin-5-ones (III) are commonly known as unsaturated azlactones. The classical Erlenmeyer azlactone synthesis ${ }^{9}$ reported the formation of 4Benzylidine-2-phenyl -2-oxazolin-5-one by the cyclization of hippuric acid with the aid of acetic anhydride and fused sodium acetate. The Erlenmeyer unsaturated azlactones have further been synthesized by using N, N-Dimethylchloro sulphite methaniminium chloride ${ }^{10}$, Phenyl isothiocyanate ${ }^{11}$, Arylsulphonyl chloride ${ }^{12}$, using microwaves on solid support ${ }^{13,14}$, sonochemical reaction in ionic liquids ${ }^{15}$, mechanochemical approach ${ }^{16}$ etc. In most of the cases, usually the stable geometric isomer with Z-configuration is obtained. Although the stable isomer of 4-Benzyledene-2-phenyl 2-oxazolin-5-one (IIIa; $\mathrm{R}=\mathrm{Ph}, \mathrm{R}^{2}=\mathrm{Ph}, \mathrm{R}^{3}=\mathrm{H}$ ) has been known for a long time.

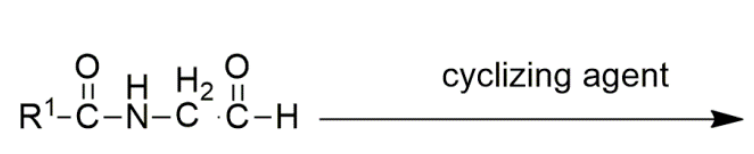

(I)

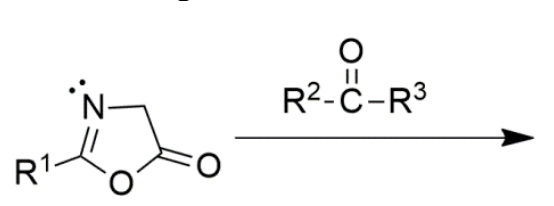

(II)<smiles>[R]C1=CC(=C([R])[R])C(=O)O1</smiles>

(III)

(IIIa) $\mathrm{R}^{2}=\mathrm{Aryl} / \mathrm{Alkyl}$ and $\mathrm{R}^{3}=\mathrm{H}$; (Z)- isomer of azlactone (IIIb) $\mathrm{R}^{2}=\mathrm{H}$; and $\mathrm{R}^{3}=$ Aryl/ Alkyl; $(E)$ - isomer of azlactone 


\section{International Advanced Research Journal in Science, Engineering and Technology}

Vol. 8, Issue 6, June 2021

\section{DOI: $10.17148 / I A R J S E T .2021 .8655$}

But its geometric isomer was not reported until 1941. The possibility of the existence of geometric isomers was indicated for 4-Cinnamylidene-2-phenyl-2-oxazolin-5-one (IIIa; $\mathrm{R}^{2}=\mathrm{CH}=\mathrm{CH}-\mathrm{Ph}, \mathrm{R}^{3}=\mathrm{H}, \mathrm{R}^{1}=\mathrm{Ph}$ and $\mathrm{IIIb} ; \mathrm{R}^{2}=\mathrm{H}, \mathrm{R}^{3}=$ $\mathrm{CH}=\mathrm{CH}-\mathrm{Ph}, \mathrm{R}^{1}=\mathrm{Ph}$ ) but the isomers were not isolated. 4-Arylidene-2-phenyl-2-oxazolin-5-ones are also useful precursors particularly for the synthesis of amino acids ${ }^{17}$, their corresponding esters ${ }^{17}$, anilides ${ }^{18}$ and peptides ${ }^{19,20}$ and other biologically active compounds.

The objective of the present investigation was to develop a method for a fast and facile synthesis of $(E)$ - and $(Z)$ isomers of 4-cinnamylidene-2-phenyl-2-oxazolin-5-ones separately by using non- conventional green chemistry methodology which led to better yield of each isomer in pure form and a remarkable reaction rate enhancement with optimum utilization of energy. The conversion of $\alpha-\mathrm{N}-$ Benzoyl glycine i.e. Hippuric acid (1) to unstable 2-phenyl-2oxazolin-5-one (2) was carried out in dry benzene using either ethyl chloroformate or benzene sulphonyl chloride or $p$ toluene sulphonyl chloride as cyclizing agent in the presence of triethylamine base at room temperature which declined the risk of high pressure development associated with solution phase reaction at high temperature as well. After condensation of cinnamaldehyde with (2), the content is refluxed for 10 minutes, the solvent was removed under reduced pressure and reused. The finding unsaturated azlactone, $(E)$-4-cinnamylidene-2-phenyl-2-oxazolin-5-one (3) can be isolated by triturating it with ethanol or may be subjected to solvolysis directly. Hydrolysis, alcoholysis and aminolysis of (E)-4-cinnamylidene-2-phenyl-2-oxazolin-5-one (3) leads to the formation of corresponding dehydroamino acid (4), esters of dehydroamino acid (5) and alkenamide (6) respectively by the cleavage of 1,5 - bond of the azlactone (3) with $(E)$-configuration maintaining the steric integrity at 4-position of $(E)$-azlactone. $(E)$-azlactone (3) can be converted to (Z)-azlactone (7) by boiling it in dry pyridine for 15 minutes. Similar way, the solvolysis of 1,5 bond of (Z)-isomer of 4-cinnamylidene-2-phenyl-2-oxazolin-5-one (7) affords the solvolysis products with (Z)configuration. For each of the product formation, all the required steps are carried out in the same flask.

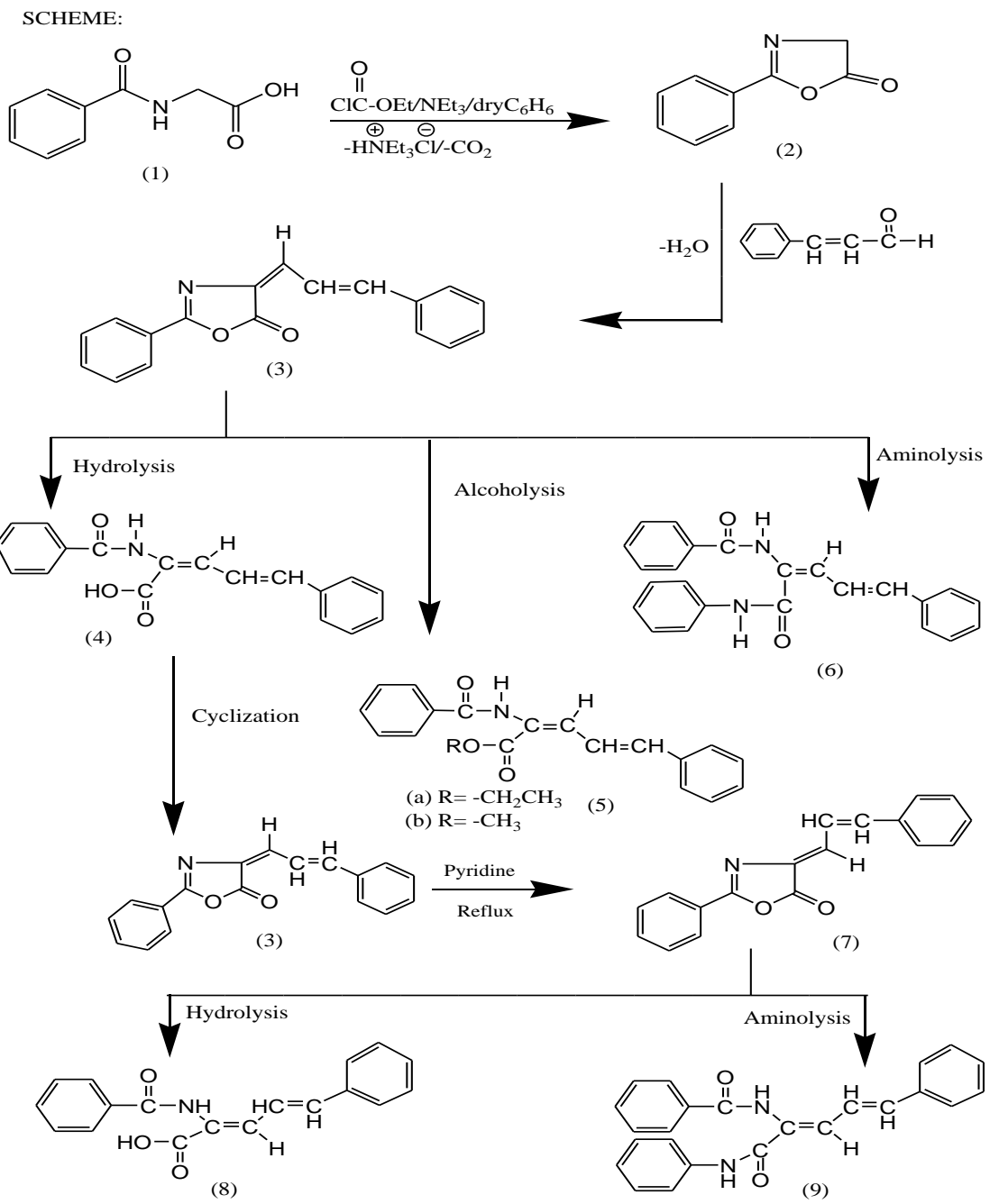

Figure-1: Synthesis of $(E)$ - and $(Z)$ - 4-Cinnamylidene-2-phenyl-2-oxazolin-5-ones and their stereospecific solvolytic products. 


\section{DOI: 10.17148/IARJSET.2021.8655}

\section{MATERIALS AND METHODS}

All the prepared compounds are known in the Literature $5,16,17,18$. The purity of the synthesized compounds were verified by TLC (Silica gel based/Benzene) and their melting points. Melting points were recorded by metal block melting point apparatus and are uncorrected. The IR, UV-spectra and ${ }^{1} \mathrm{H}-\mathrm{NMR}$ of the compounds were recorded on IR Affinity-1, Shimadzu, Cary-14 and Varian AS400 spectrophotometers respectively.

\subsection{Synthesis of $(E)$-4-Cinnamylidene-2-phenyl-2-oxazolin-5-one (3) using} Ethyl chloroformate as cyclocondensing agent.

To a stirred suspension of $\alpha-\mathrm{N}$-benzoylglycine $(1,1.0 \mathrm{~mol})$ in dry benzene $(30 \mathrm{~mL} / \mathrm{g}$ of 1$)$ containing triethylamine $(1.2$ $\mathrm{mol})$, ethyl chloroformate $(1.1 \mathrm{~mol})$ was added and the mixture was shaken at room temperature until the acid crystals dissolved and triethylamine salts separated out. The aromatic aldehyde (Cinnamaldehyde, 1.0 mol) was added to the mixture which was then heated under reflux for about 10 minutes. Triethylamine salts were filtered off under suction and washed twice with dry benzene $(5 \mathrm{~mL}$ each). The benzene solution and washings were combined and concentrated to dryness under vacuum. The residue was triturated with ethanol to afford the title compound, which was filtered and recrystallized from ethanol. Yield: $75 \%$, m.p.: $141-143^{\circ} \mathrm{C}\left(\operatorname{Reported}^{5}: 143^{\circ} \mathrm{C}\right), \mathrm{IR}(\mathrm{KBr}): v\left[\mathrm{~cm}^{-1}\right]=1788(\mathrm{C}=\mathrm{O}$, oxazolone), $1770(\mathrm{C}=\mathrm{N}), 1653(\mathrm{C}=\mathrm{C}), 1594(\mathrm{C}=\mathrm{C}), \mathrm{UV}(95 \%$ Ethanol $) \lambda[\mathrm{nm}]\left(\in \times 10^{-4}\right) 300(3.95),{ }^{1} \mathrm{H} \mathrm{NMR}(300 \mathrm{MHz}$, DMSO-d 6 ): $\delta 7.27(\mathrm{~d}, 1 \mathrm{H}, \mathrm{C} \underline{\mathrm{H}}=\mathrm{C}, \mathrm{J}=11.4 \mathrm{~Hz}), 7.36-7.42(\mathrm{~m}, 4 \mathrm{H}, \operatorname{Ar}-\underline{\mathrm{H}}), 7.57-7.68(\mathrm{~m}, 7 \mathrm{H}, 6 \mathrm{Ar}-\underline{\mathrm{H}}+1 \mathrm{C} \underline{\mathrm{H}}=\mathrm{C}), 8.08(\mathrm{~d}$, $1 \mathrm{H}, \mathrm{C} \underline{\mathrm{H}}=\mathrm{C}), \mathrm{J}=12.0 \mathrm{~Hz}) \mathrm{ppm}$.

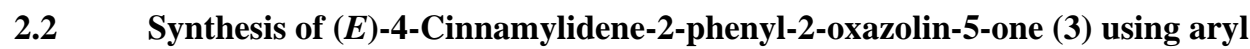
sulphonyl chloride as cylocondensing agent.

To a stirred suspension of $\alpha-\mathrm{N}$-benzoylglycine $(1,1.0 \mathrm{~mol})$ in dry benzene $(30 \mathrm{~mL} / \mathrm{g}$ of 1$)$ containing triethylamine $(2.5$ mol), benzenesulphonyl chloride $(1.0 \mathrm{~mol})$ or $p$-toluenesulphonyl chloride $(1.0 \mathrm{~mol})$ was added and the mixture was shaken at room temperature until the acid crystals dissolved and triethylamine salts separated out. The aromatic aldehyde (Cinnamaldehyde, $1.0 \mathrm{~mol}$ ) was added to the mixture which was then heated under reflux for about 10 minutes. Triethylamine salts were filtered off under suction and washed twice with dry benzene ( $5 \mathrm{~mL}$ each). The benzene solution and washings were combined and concentrated to dryness under vacuum. The residue was triturated with ethanol to afford the title compound, which was filtered and recrystallized from ethanol. Yield: $70 \%$ (using Benzenesulphonyl chloride) and Yield: $73 \%$ (using $p$-Toluenesulphonyl chloride) m.p.: 141-143 ${ }^{\circ} \mathrm{C}\left(\operatorname{Reported}^{5}\right.$ : $\left.143^{\circ} \mathrm{C}\right)$.

\subsection{Synthesis of $(Z)-4-C i n n a m y l i d e n e-2-p h e n y l-2-o x a z o l i n-5-o n e ~(7)$}

(E)-4-Cinnamylidene- 2-phenyl-2- oxazolin-5-one (3) as prepared either using Method 2.1 or Method 2.2 was heated with dry Pyridine $(10 \mathrm{~mL} / \mathrm{g}$ of 3 ) for about 15 minutes. On cooling, the content was poured into the crushed ice (80$90 \mathrm{~g} / \mathrm{g}$ of 3). The dark yellow solid obtained was filtered under suction. The residue was dried and recrystallized from ethanol. Yield: $90 \%$, m.p.: $150-152^{\circ} \mathrm{C}$ (Reported $\left.{ }^{5,17}: 152^{\circ} \mathrm{C}\right) .{ }^{1} \mathrm{H}$ NMR $\left(300 \mathrm{MHz}, \mathrm{DMSO}-\mathrm{d}_{6}\right): \delta 7.27(\mathrm{~d}, 1 \mathrm{H}, \mathrm{C} \underline{H}=\mathrm{C}$, $\mathrm{J}=16.4 \mathrm{~Hz}), 7.36-7.42(\mathrm{~m}, 4 \mathrm{H}, \mathrm{Ar}-\underline{\mathrm{H}}), 7.57-7.68(\mathrm{~m}, 7 \mathrm{H}, 6 \mathrm{Ar}-\underline{\mathrm{H}}+1 \mathrm{C} \underline{\mathrm{H}}=\mathrm{C}), 8.08$ (d, 1H, C$=\mathrm{C}), \mathrm{J}=12.0 \mathrm{~Hz}) \mathrm{ppm}$.

2.4 Synthesis of (Z)-4-Cinnamylidene-2-phenyl-2-oxazolin-5-one (7) using acetic anhydride and fused sodium acetate (The classical Erlenmeyer Azlactone Synthesis).

Hippuric acid (4.5g, 0.025mol); Cinnamaldehyde (3.3mL, 0.025mol); Acetic anhydride(7.15mL, 0.075mol); Anhydrous sodium acetate $(2.05 \mathrm{~g}, 0.025 \mathrm{~mol})$ was added in a $250 \mathrm{~mL}$ round bottom flask and heated on a hot plate with constant stirring. As soon as the mixture was liquefied completely, the round bottom flask was transferred to a water bath and was refluxed for 2 hours. $10 \mathrm{~mL}$ EtOH was added slowly to the contents of the round bottom flask and allowed the mixture to stand overnight. The crystalline product was filtered with suction, and washed with two $2.5 \mathrm{~mL}$ portion of ice cold alcohol and then washed with two $2.5 \mathrm{~mL}$ portion of boiling water. Content was dried at $100^{\circ} \mathrm{C}$. The reaction yielded a mixture of $(E+Z)$ - isomer, m.p., $=118^{\circ} \mathrm{C}-136^{\circ} \mathrm{C}$. The mixture was subjected to hydrolysis without separation by aqueous $\mathrm{KOH}$.

Hydrolysis by aqueous $\mathrm{KOH}$ was performed by adding the above mixture $(1.375 \mathrm{~g}, 0.005 \mathrm{~mol}), \mathrm{KOH}(0.0336 \mathrm{~g}$, $0.006 \mathrm{~mol}$ ) and water $40 \mathrm{~mL}$ in a round bottom flask and then heated under reflux for about $30 \mathrm{~min}$ to get a clear solution. The solution was then chilled and acidified with concentrated $\mathrm{HCl}$ till complete precipitation. The precipitated acid was filtered and then the resultant acid derivative was recyclized using cyclizing agent like $\mathrm{Ac}_{2} \mathrm{O} / \mathrm{CH}_{3} \mathrm{COONa}$. The product was re-crystallized from aqueous ethanol. Yield: 50\%, m.p.: 150-152 ${ }^{\circ} \mathrm{C}\left(\operatorname{Reported}^{5,17}: 152^{\circ} \mathrm{C}\right)$.

\subsection{Hydrolysis of $(E)$-4-cinnamylidene-2-phenyl-2-oxazolin-5-one (3), Formation of $(E)$-2-}

benzoylamino-3-styrylprop-2-enoic acid (4)

To the compound (E)-4-cinnamylidene-2-phenyl-2-oxazolin-5-one (3) prepared by using either Method 2.1 or Method 


\section{International Advanced Research Journal in Science, Engineering and Technology}

Vol. 8, Issue 6, June 2021

\section{DOI: 10.17148/IARJSET.2021.8655}

2.2 after concentrating to dryness under vacuum, potassium hydroxide $(1.2 \mathrm{~mol})$ and $95 \%$ ethanol $(80 \mathrm{~mL} / \mathrm{g} \mathrm{of} \mathrm{KOH})$ were added in the same flask and the mixture was shaken at room temperature until the $\mathrm{KOH}$ pellets had completely dissolved. The mixture was then heated under reflux for about 15 minutes. The solution thus obtained was evaporated under reduced pressure. The residue was stirred with Chilled water $(15 \mathrm{~mL} / \mathrm{g}$ of 1$)$ and the mixture was filtered by suction. The insoluble ester, obtained in small amount, can be purified by recrystallization from aqueous ethanol. The filtrate was acidified with conc. Hydrochloric acid with cooling; the precipitated acid, (E)-2-benzoylamino-5phenylpenta-2,4-dienoic acid or (E)-2-benzoylamino -3-styrylprop-2-enoic acid (4) was isolated by suction and recrystallized from aqueous ethanol. Yield: $71 \%$, m.p.: $229-231^{\circ} \mathrm{C}\left(\operatorname{Reported}^{17}: 230-232^{\circ} \mathrm{C}\right)$

IR (KBr): $v\left[\mathrm{~cm}^{-1}\right]=3280(-\mathrm{OH}), 1695(\mathrm{C}=\mathrm{O}$, acid $), 1655(\mathrm{C}=\mathrm{O}$, amide $), 1645(\mathrm{C}=\mathrm{C}), 1620(\mathrm{C}=\mathrm{C}) ; 1610(\mathrm{C}=\mathrm{O}$, aromatic).

$\mathrm{UV}(95 \%$ ethanol $), \lambda[\mathrm{nm}]\left(\in \times 10^{-4}\right): 327(2.42)(\mathrm{C}=\mathrm{O}), 234(1.06)(\mathrm{C}=\mathrm{C}), 222(0.84)(\mathrm{C}=\mathrm{C})$.

\subsection{Alcoholysis of $(E)$-4-cinnamylidene-2-phenyl-2-oxazolin-5-one (3)}

\subsubsection{Ethanolysis: Formation of $(E)$-Ethyl 2-benzoylamino-3-styrylprop-2-enoate (5a)}

The compound (E)-4-cinnamylidene-2-phenyl-2-oxazolin-5-one (3) prepared by using either Method 2.1 or Method 2.2 after concentrating to dryness under vacuum, was treated with $95 \%$ ethanol $(30 \mathrm{~mL} / \mathrm{g}$ of 1$)$ in the presence of catalytic amount of $\mathrm{KOH}(1 / 2$ pellet) in the same flask. The mixture was refluxed for $15-20 \mathrm{~min}$, and then concentrated to dryness under reduced pressure. The residue was triturated with chilled water. The solid material was isolated by suction, washed twice with cold water and recrystallized from ethanol. The product obtained is $(E)$ - Ethyl 2benzoylamino-2-phenylpenta-2,4-dienoate or $(E)$-Ethyl 2-benzoylamino-3-styrylprop-2-enoate (5a) which may also be recrystallised from benzene, petroleum ether (b.p. $40-60^{\circ} \mathrm{C}$ ) mixture. Yield: 55\%, m.p.: 118-120 ${ }^{\circ} \mathrm{C}\left(\right.$ Reported $^{17}$ : $121-$ $\left.123^{\circ} \mathrm{C}\right)$

IR $(\mathrm{KBr}): v\left[\mathrm{~cm}^{-1}\right]=3280(-\mathrm{NH}), 1710(\mathrm{C}=\mathrm{O}$, ester $), 1650(\mathrm{C}=\mathrm{O}$, amide $), 1645(\mathrm{C}=\mathrm{C}), 1620(\mathrm{C}=\mathrm{C}$, styryl $), 1610(\mathrm{C}=\mathrm{C}$, aromatic) .

${ }^{1} \mathrm{H} \mathrm{NMR}\left(\mathrm{CDCl}_{3} / \mathrm{TMS}_{\text {int }}\right): \delta=1.4\left(\mathrm{t}, 3 \mathrm{H}, \mathrm{CH}_{2}-\underline{\mathrm{CH}}_{3}\right), 4.44\left(\mathrm{q}, 2 \mathrm{H}, \mathrm{O}-\mathrm{C}_{2}-\mathrm{CH}_{3}\right), 6.9-7.16(\mathrm{~m}, 2 \mathrm{H}$,

$-\mathrm{C} \underline{\mathrm{H}}=\mathrm{C} \underline{\mathrm{H}}-)$ ) 7.3-8.2(m, 12H, $\mathrm{N} \underline{\mathrm{H}}+\mathrm{Ph}-\mathrm{C} \underline{\mathrm{H}}=+\mathrm{Ar}-\underline{\mathrm{H}}) \mathrm{ppm}$.

\subsubsection{Methanolysis: Formation of $(E)$-Methyl 2-benzoylamino-3-styrylprop-2-enoate (5b)}

The compound (E)-4-cinnamylidene-2-phenyl-2-oxazolin-5-one (3) prepared by using either Method 2.1 or Method 2.2 after concentrating to dryness under vacuum, was treated with $100 \%$ methanol $(30 \mathrm{~mL} / \mathrm{g}$ of 1$)$ in the presence of a catalytic amount of metallic sodium $(0.07 \mathrm{~g}$ per $1.0 \mathrm{~g}$ of 1$)$ in the same flask. The mixture was refluxed for $15-20 \mathrm{~min}$, and then concentrated to dryness under reduced pressure. The residue was triturated with chilled water $(10-15 \mathrm{~mL} / \mathrm{g}$ of 1). The solid material was isolated by suction, washed twice with cold water and recrystallized from methanol. The product may also be recrystallized from benzene / petroleum ether (b.p. $40-60^{\circ} \mathrm{C}$ ). The product obtained is

(E)- Methyl 2-benzoylamino-2-phenylpenta-2,4-dienoate or (E)-Methyl 2-benzoylamino-3-styrylprop-2-enoate (5b) . Yield: $60 \%$, m.p.: $158-160^{\circ} \mathrm{C}$ (Reported $\left.{ }^{17}: 160-161^{\circ} \mathrm{C}\right)$

IR (KBr): $v\left[\mathrm{~cm}^{-1}\right]=3270(-\mathrm{NH}) ; 1715(\mathrm{C}=\mathrm{O}$, ester $), 1655(\mathrm{C}=\mathrm{O}$, amide $), 1645(\mathrm{C}=\mathrm{C}), 1625(\mathrm{C}=\mathrm{C}$, styryl $)$.

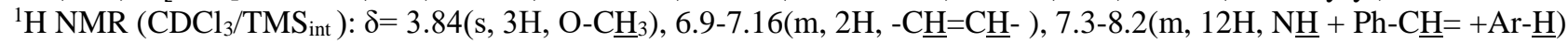
ppm.

2.7 Aminolysis of $(E)$-4-cinnamylidene-2-phenyl-2-oxazolin-5-one (3),

Anilinolysis: Formation of $(E)$-2-benzoylamino-N-phenyl-3-styrylprop-2-enamide (6)

The compound (E)-4-cinnamylidene-2-phenyl-2-oxazolin-5-one (3) prepared by using either Method 2.1 or Method 2.2 after concentrating to dryness under vacuum, the aniline $(1.2 \mathrm{~mol})$ and the glacial acetic acid $(3-4 \mathrm{~mL} / \mathrm{g}$ of 1$) \mathrm{were}$ added and mixture was heated under reflux for 5-10 min. On cooling, a solid separated out which was isolated by suction and washed with benzene. The product (E)-2-benzoylamino-N,5-diphenylpenta-2,4-dienamide or (E)-2benzoylamino-N-phenyl-3-styrylprop-2-enamide (6) was recrystallized from ethanol.

Yield: $60 \%$, m.p.: $252-254^{\circ} \mathrm{C}$ (Reported $\left.^{18}: 253-254^{\circ} \mathrm{C}\right), \quad$ IR $(\mathrm{KBr}): v\left[\mathrm{~cm}^{-1}\right]=3340(-\mathrm{NH}), 3240(-\mathrm{NH}), 1660(\mathrm{C}=\mathrm{O}$, amide), $1640(\mathrm{C}=\mathrm{C}) . \mathrm{UV}\left(95 \%\right.$ ethanol), $\lambda[\mathrm{nm}]\left(\epsilon \times 10^{-4}\right): 330(3.25)(\mathrm{C}=\mathrm{O}), 235(2.01)(\mathrm{C}=\mathrm{C})$.

\subsection{Hydrolysis of ( $Z$ )-4-cinnamylidene-2-phenyl-2-oxazolin-5-one (7), Formation of (Z)-2-benzoylamino-3- styrylprop-2-enoic acid (8)}

(Z)-4-cinnamylidene-2-phenyl-2-oxazolin-5-one (7) (1.0 mol) as prepared by using either Method 2.3 or Method 2.4, was treated with potassium hydroxide $(1.2 \mathrm{~mol})$ and $95 \%$ ethanol $(80 \mathrm{~mL} / \mathrm{g}$ of $\mathrm{KOH})$ and the mixture was shaken at room temperature until the $\mathrm{KOH}$ pellets had completely dissolved. The mixture was then heated under reflux for about 15 minutes. The solution thus obtained was evaporated under reduced pressure. The residue was stirred with chilled water $(15 \mathrm{~mL} / \mathrm{g}$ of 7$)$ and the mixture was filtered by suction. The insoluble ester was obtained in small amount. The filtrate was acidified with conc. Hydrochloric acid with cooling; the precipitated acid, (Z)-2-benzoylamino-2- 


\section{International Advanced Research Journal in Science, Engineering and Technology}

Vol. 8, Issue 6, June 2021

\section{DOI: 10.17148/IARJSET.2021.8655}

phenylpenta-2,4-dienoic acid or (Z)-2- benzoylamino-3-styrylprop-2-enoic acid (8) was isolated by suction and recrystallized from aqueous ethanol. Yield: $70 \%$, m.p.: 235-237 ${ }^{\circ} \mathrm{C}\left(\operatorname{Reported}^{17}: 236-238^{\circ} \mathrm{C}\right), \mathrm{IR}(\mathrm{KBr}): v\left[\mathrm{~cm}^{-1}\right]=$ 3370 (-NH, amide), $3280(-\mathrm{OH}), 1695(\mathrm{C}=\mathrm{O}$, acid), $1655(\mathrm{C}=\mathrm{O}$, amide), $1645(\mathrm{C}=\mathrm{C}), 1620(\mathrm{C}=\mathrm{C}), 1610(\mathrm{C}=\mathrm{C}$, aromatic). UV (95\% ethanol), $\lambda[\mathrm{nm}]\left(\epsilon \times 10^{-4}\right): 327(1.98)(\mathrm{C}=\mathrm{O}), 234(0.81)(\mathrm{C}=\mathrm{C}), 222(0.84)(\mathrm{C}=\mathrm{C})$.

\subsection{Aminolysis of (Z)-4-cinnamylidene-2-phenyl-2-oxazolin-5-one (7), Anilinolysis: Formation of $(Z)$-2-benzoylamino-N-phenyl-3-styrylprop-2-enamide (9)}

(Z)-4-cinnamylidene-2-phenyl-2-oxazolin-5-one (7) (1.0 mol) as prepared by using either Method 2.3 or Method 2.4, in dry benzene $(20 \mathrm{~mL} / \mathrm{g}$ of 7$)$, the aniline $(1.2 \mathrm{~mol})$ and the glacial acetic acid $(3-4 \mathrm{~mL} / \mathrm{g}$ of 7$)$ were added and mixture was heated under reflux for 5-10 min. On cooling, a solid separated out which was isolated by suction and washed with benzene. The product obtained (Z)-2-benzoylamino-N,5-diphenylpenta-2,4-dienamide or ( $Z$ )-2-benzoylamino-Nphenyl-3-styrylprop-2-enamide (9) was recrystallized from ethanol.

Yield: $78 \%$, m.p.: $246-248^{\circ} \mathrm{C}$ (Reported $\left.^{18}: 247-248^{\circ} \mathrm{C}\right), \quad \mathrm{IR}(\mathrm{KBr}): v\left[\mathrm{~cm}^{-1}\right]=3340(-\mathrm{NH}), 3240(-\mathrm{NH}), 1660(\mathrm{C}=\mathrm{O}$, amide), $1645(\mathrm{C}=\mathrm{C})$. UV (95\% ethanol), $\lambda[\mathrm{nm}]\left(\epsilon \times 10^{-4}\right): 330(4.10)(\mathrm{C}=\mathrm{O}), 235(2.45)(\mathrm{C}=\mathrm{C})$.

2.10 Recyclization of $(E)$-2-benzoylamino-5-phenylpenta-2,4-dienoic acid (4) to (E)-4- cinnamylidene-2-phenyl2-oxazolin-5-one( 3 ) and its conversion to corresponding $(Z)$ - isomer (7).

To a continuous stirred suspension of $(E)$-2-benzoylamino-5-phenylpenta-2,4-dienoic acid (4, 1.0 mol) in dry benzene $(30 \mathrm{~mL} / \mathrm{g}$ of 4$)$ containing triethylamine $(1.2 \mathrm{~mol})$, ethylchloroformate $(1.1 \mathrm{~mol})$ was added and the mixture was shaken at room temperature until the acid crystals (4) dissolved. The time required is 15- 20 minutes. Triethylamine salts were filtered off through suction and washed twice with dry benzene. The washings and benzene solutions were combined and concentrated to dryness under vacuum. The residue was triturated with chilled $95 \%$ ethanol. The solid material was isolated by suction, washed with chilled ethanol and recrystillised from ethanol. The product obtained is $(E)-4-$ cinnamylidene-2-phenyl-2-oxazolin-5-one (3).

The compound $3(1.0 \mathrm{~mol})$ was heated with dry Pyridine $(10 \mathrm{~mL} / \mathrm{g}$ of 3$)$ for 15 minutes. On cooling, the content was poured in crushed ice $(50-80 \mathrm{~g} / \mathrm{g}$ of 3 ) and the solid obtained was filtered under suction. The compound isolated was (Z)-4-cinnamylidene-2-phenyl-2-oxazolin-5-one (7) which was recrystallized from 95\% ethanol. Yield: 90\%; m.p.: $152^{\circ} \mathrm{C}$ (Reported $\left.^{5}: 152^{\circ} \mathrm{C}\right)$

\section{RESULT}

$\alpha$-N-Benzoylglycine (1) is converted into 2-phenyl-2-oxazolin-5-one (2) by using the cyclocondensing agent either ethyl chloroformate or benzenesulfonyl chloride or $p$ - toluene sulfonyl chloride in dry benzene in the presence of triethylamine base at room temperature. In case of ethyl chloroformate, $1.2 \mathrm{~mol}$ of triethylamine is used. Whereas, 2.5 mol of triethylamine is required for aryl sulphonyl chloride to separate the salt crystals formed. Subsequent treatment with Cinnamaldehyde and heating of the mixture at reflux temperature for 10 minutes affords the unsaturated azlactone i.e., 4-Cinnamylidene-2-phenyl-2-oxazolin-5-one (3) with geometric isomer of (E)-configuration under present experimental conditions. $(E)$-Azlactones are thermolabile and can easily be isomerizesd to corresponding $(Z)$-isomer by boiling the $(E)$-isomer in dry pyridine for 15 minutes. Therefore, $(E)$-4-Cinnamylidene-2-phenyl-2-oxazolin-5-one can be converted to $(Z)$ - 4-Cinnamylidene-2-phenyl-2-oxazoline-5-one by boiling it with pyridine.

The intermediate 4-Cinnamylidene-2-phenyl -2-oxazolin-5-one (3) obtained by this method have the $(E)$-configuration. The $(Z)$-isomer is obtained by isomerisation of the $(E)$-compound (3) by heating in dry pyridine for 15 minutes. $(E)$ isomer of 4-cinnamylidene -2- phenyl -2-oxazolin -5-one (3) affords the corresponding acid (4) esters (5a and 5b) and anilide (6) with $(E)$-configuration on solvolysis. At the same time, $(Z)$-isomer of 4-cinnamylidene-2-phenyl-2-oxazolin5-one (7) gives the solvolysis products with $(Z)$-configuration.

\section{DISCUSSION}

The result for the formation of 4-Cinnamylidene-2-phenyl -2-oxazolin-5-one (3) is obviously due to the aldol type condensation of aldehyde at 4 position of active methylene of the intermediate 2 with the elimination of water molecule. The Crude product, 4-Cinnamylidene-2-phenyl-2-oxazolin-5-one (3), with (E)- configuration obtained by removing solvent under reduced pressure is directly subjected to 1.5-band cleavage using solvolysis namely hydrolysis, alcoholysis and aminolysis. Hydrolysis is carried out by heating with aqueous $\mathrm{KOH}$ or ethanolic $\mathrm{KOH}$, followed by acidification with conc. $\mathrm{HCl}$ which affords $(E)$ - 2- Benzoylamino-5-phenylpenta-2,4-dienoic acid or $(E)$-2Benzoylamino-3-styrylprop-2-enoic acid (4). The result is obviously due the generation of hydroxide ion as nucleophile which brings about the cleavage of the 1,5-bond of compound 3. When ethanolic $\mathrm{KOH}$ is used, a small amount of the corresponding ethyl ester 5a is also obtained. The ethyl ester, Ethyl 2-benzoylamino-5-phenylpenta- 2,4-dienoate or Ethyl 2-benzoylamino- 3- styrylprop-2-enoate (5a), may be obtained in much better yield by treating the compound (3) 


\section{International Advanced Research Journal in Science, Engineering and Technology}

Vol. 8, Issue 6, June 2021

\section{DOI: 10.17148/IARJSET.2021.8655}

with $95 \%$ ethanol presence of the catalytic amount $\mathrm{KOH}$ (ethanolysis). It is due to the generation of ethoxide ion as nucleophile which cleaves the 1,5-bond of compound $\mathbf{3}$ with the formation of the product 5a. In continuation of alcoholysis, methanolysis is also carried out in methanol using a catalytic amount of sodium metal. In this case, the generated methoxide ion as nucleophile cleaves the 1, 5 bond of Compound 3 and leads to the formation of corresponding methyl ester which is methyl 2-benzoylamino-5-phenylpenta-2,4-dienoate or methyl 2-benzoylamino-3styrylprop-2-enoate (5b). Both the compound $\mathbf{5 a}$ and $\mathbf{5 b}$ have $(E)$-configuration. For aminolyais, the $(E)$-isomer of the compound 3 is heated with aniline in glacial acetic acid for 10 minutes. On cooling the crystals of the product 2 benzoylamino- N-phenyl-3-styrylprop-2-enamide (6) separates out. It follows the attack of the lone pair of election on the $\mathrm{N}$-atom of the aniline which leads the cleavage of the 1,5-bond of the compound 3 (anilinolysis).

The (E)-4-Cinnamylidene-2-phenyl-2-oxazolin-5-one (3) obtained by the cyclocondensation from $\alpha$-N- benzoylglycine (1) and Cinnamaldehyde with cyclizing agent in the presence of triethylamine in benzene, is converted to (Z)-4Cinnamylidene - 2-phenyl-2-oxazolin-5-one (7) by heating with pyridine for 15 minutes. The corresponding $(Z)$ isomer of 4- cinnamylidene - 2-phenyl-2-oxazolin-5-one (7) is subjected to 1,5-bond cleavage via solvolysis.

On hydrolysis and anilinolysis, the corresponding acid (8) and anilide (9) are obtained respectively with their (Z)configuration. The products are recrystallized from ethanol and the purity of the compounds are verified by and TLC. The compounds are characterized by IR spectra and their reported melting points.

The typical IR absorption bonds for 5(4H)-Oxazolone (compounds 3 and 7), carboxylic acid group (compounds 4 and

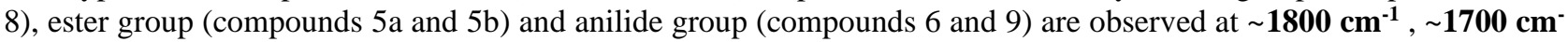
$1, \sim 1720 \mathrm{~cm}^{-1}$ and $\sim 1660 \mathrm{~cm}^{-1}$ respectively.

It is noteworthy that the intermediate 4-Cinnamylidene-2-phenyl -2-oxazolin-5-one (3) obtained by this method have the $(E)$-configuration. The $(Z)$-isomer is obtained by isomerisation of the $(E)$-compound (3) by heating in dry pyridine for 15 minutes. $(E)$-isomer (3) is thermolabile and isomerised to corresponding $(Z)$ isomers $(7)$. (E)-isomer of 4cinnamylidene -2- phenyl -2-oxazolin -5-one (3) affords the corresponding acid (4) esters (5a and 5b) and anilide (6) with $(E)$-configuration on solvolysis. At the same time, $(Z)$-isomer of 4-cinnamylidene-2-phenyl-2-oxazolin-5-one (7) gives the solvolysis products with $(Z)$-configuration. It is found that the cleavage of the 1,5 -bond in $(E)$ - and $(Z)$ isomers does not change the stereochemistry of the olefinic centre at the C-4 position. The steric integrity is further verified by the recyclization of $(E)$-acid (4) into ( $E$ )-oxazolone (3) using ethyl chloroformate in the presence of triethylamine in dry benzene. The solvolysis of $(E)$ - and (Z)-4-cinnamylidene-2-phenyl-2-oxazolin-5-one is purely stereospecific. The present procedure does not have same of the drawbacks of the other methods. For example, the Erlenmeyer azlactone synthesis employs acetic anhydride for cyclization and it affords a mixture of $(E)$ - and $(Z)$ isomers of the unsaturated azlactones which have to be separated by fractional crystallizations before using them for solvolysis. This is rather time consuming and it lowers the overall yields of the solvolytic products. The present procedure is quite convenient and the crude $(E)$-oxazolone is subjected to hydrolysis, alcoholysis and aminolysis without isolation, so that the reaction are carried out in the same flask. (E)-oxazolone can also be smoothly converted to $(Z)$-oxazolone and can be subjected to solvolysis to get solvolytic products with (Z)-configuration. The steric integrity of the solvolytic products is maintained at the same time.

\section{CONCLUSION}

The present procedure overcomes some of the disadvantages of the earlier methods ${ }^{5}$ regarding speed of the reaction and stereochemical purity of the products. It should be emphasized that the present procedure is simple and straight forward and all the steps can be carried out in one flask. Considering the easy availability of the starting material, the speed of the reaction, the milder experimental conditions, purity of the geometric isomers of synthesized products and the simplicity of the work-up, the present method appears to be potentially useful.

\section{REFERENCES}

[1]. Carter HE, Organic Reactions, John Wiley and Sons, New York, 1947; 3:198-239.

[2]. Cornforth JW, 'The Chemistry of Penicillin', H.T. Clarke, J.R. Johnson and R. Robinson, Eds. Princeton University Press, 1949; 688-848.

[3]. Cornforth JW, 'Heterocyclic Compounds', R.C. Elderfield, Ed. John Wiley and Sons, New York, 1957); 5 : 298-417.

[4]. Filler R, Adv. Heterocyclic Chemistry, Academic Press Inc. New York, 1965; 4: 75-106.

[5]. Rao YS and Filler R, Geometric Isomers of 2-Aryl(Aralkyl)-4-arylidene(alkylidene)-5(4H)-oxazolones, Synthesis, 1975 ; $749-764$.

[6]. (a) Mukerjee AK and Kumar P, The Chemistry of 4,5-Dihydro-5-oxo-1,3-oxazoles, Heterocycles, 1981; 16(11): 1995-2034. (b) Mukerjee AK, Azlactones: Retrospect and Prospect, Heterocycles, 1987; 26:1077-1097.

[7]. Haneen DSA, Abou- Elmagd WSI and Youssef ASA, 5(4H)-Oxazolones: Synthesis and biological activities, Synthetic Communications, 2020; DOI: 10.1080/ 00397911. 2020. 1825746. Link: https://doi.org/10.1080/ 00397911. 2020. 1825746.

[8]. Sharada LN, Aparna Y, Saba M, Sunitha SNT and Viveka L, A review on reactions and applications of Oxazolones, International J. of Scientific and Research Publications, 2015; 5(6):1-9.

[9]. Erlenmeyer E and Matter O, Liebigs Ann. Chem, 1904; 337: 271-273.

[10]. Sain Bir, Singh SP and Sandhu JS, A facile synthesis of 4-arylidene-2-oxazolin-5-ones by using N,N-dimethylchlorosulphite methaniminium chloride as cyclodehydrating agent, Chem. Ind. (London), 1990; 15: 499. 


\section{International Advanced Research Journal in Science, Engineering and Technology}

Vol. 8, Issue 6, June 2021

\section{DOI: 10.17148/IARJSET.2021.8655}

[11]. Mukerjee AK and Ashare Ram, Isothiocyanates in the Chemistry of Heterocycles, Chemical Reviews, 1991; 91: 1-24.

[12]. Goswami Limi and Tripathy PK, Synthesis of Erlenmeyer azlactones using Arylsulphonyl chloride as cyclocondensing agent, Indian J. Heterocyclic Chem, 2015; 24: 281-282

[13]. Mogilaiah K, Prashanthi M and Reddy Ch. Srinivas, Solid support Erlenmeyer synthesis of azlactones using microwaves, Indian J. Chem, 2003; 42B: 2126-2128

[14]. Chandrasekhar S and Karri P, Erlenmeyer azlactone synthesis with aliphatic aldehydes under solvent-free microwave conditions, Tetrahedron Letters, 2007; 48 (5): 785-786.

[15]. Heravi Md. Reza Poor, Erlenmeyer synthesis of azlactones by sonochemical reaction in ionic liquids, J. University of Chemical technology and Metallurgy, 2009; 44(1): 86-90.

[16]. Fahmy Amin FM, EL-Sayed Amina A and Hemdan Magdy M, Multicomponent synthesis of 4-arylidene-2-phenyl-5(4H) oxazolones (azlactones) using a mechanochemical approach, Chemistry Central Journal, 2016; 10: Article No. 59.

[17]. Tripathy PK and Mukerjee AK, A fast synthesis of 2-Acylamino-2-alkenoic acids, Synthesis, 1984; 418-422.

[18]. Tripathy PK and Mukerjee AK, A facile synthesis of N-Substituted 2-Acylamino-2-alkenamides, Synthesis, $1985 ; 285-288$.

[19]. Ibrahim Md. N, Saeed M and Fadhil S, Synthetic studies of dihydropeptides, J. Iraqi Chem. Soc., 1987; 12(1):159-170.

[20]. Cavelier F and Verducci J, New synthesis of the cyclic tetrapeptide tentoxin employing an azlactone as key intermediate, Tetrahedron Letters, $1995 ; 36(25): 4425-4428$ 